\title{
Theta-Modulated Place-by-Direction Cells in the Hippocampal Formation in the Rat
}

\author{
Francesca Cacucci, ${ }^{1}$ Colin Lever, ${ }^{1}$ Thomas J. Wills, ${ }^{1}$ Neil Burgess, ${ }^{1,2}$ and John 0’Keefe ${ }^{1,2}$ \\ ${ }^{1}$ Department of Anatomy and Developmental Biology and ${ }^{2}$ Institute of Cognitive Neuroscience, University College London, WC1N 3AR, London, United Kingdom
}

\begin{abstract}
We report the spatial and temporal properties of a class of cells termed theta-modulated place-by-direction (TPD) cells recorded from the presubicular and parasubicular cortices of the rat. The firing characteristics of TPD cells in open-field enclosures were compared with those of the following two other well characterized cell classes in the hippocampal formation: place and head-direction cells. Unlike place cells, which code only for the animal's location, or head-direction cells, which code only for the animal's directional heading, TPD cells code for both the location and the head direction of the animal. Their firing is also strongly theta modulated, firing primarily at the negative-to-positive phase of the locally recorded theta wave. TPD theta modulation is significantly stronger than that of place cells. In contrast, the firing of head-direction cells is not modulated by theta at all. In repeated exposures to the same environment, the locational and directional signals of TPD cells are stable. When recorded in different environments, TPD locational and directional fields can uncouple, with the locational field shifting unpredictably ("remapping"), whereas the directional preference remains similar across environments.
\end{abstract}

Key words: hippocampus; spatial; orientation; navigation; path integration; maze

\section{Introduction}

A wide body of evidence has indicated a critical role for the hippocampal formation in navigation and spatial memory (O’Keefe and Nadel, 1978; Morris et al., 1982; Barnes, 1988; Jarrard, 1993; Taube, 1998; Burgess et al., 2002). Extracellular unit recording in rodents and primates has identified the following two well characterized cell groups: place cells (PCs) in the hippocampal CA fields, which signal environment-specific location (O'Keefe, 1976; Muller and Kubie, 1987; Wilson and McNaughton, 1993; Ekstrom et al., 2003), and head-direction (HD) cells in the presubiculum (Taube et al., 1990a,b; Robertson et al., 1999), which signal orientation. Other, less well characterized cell groups include superficial-layer entorhinal cells and subicular cells that are thought to signal location in a manner that is less environment specific than place cells in the hippocampus proper (Quirk et al., 1992; Sharp and Green, 1994; Sharp, 1997, 1999a,b; Frank et al., 2000).

An additional characteristic of the hippocampal formation is the 4-12 Hz theta oscillation (Vertes and Kocsis, 1997; Bland and Oddie, 2001; Buzsaki, 2002) seen during locomotion in birds (Siegel et al., 2000) and mammals (Vanderwolf, 1969; O'Keefe and Nadel, 1978), including humans (Caplan et al., 2003). This may synchronize and sequence neuronal assemblies. For instance, theta phase can be remarkably constant across distributed fields (such as the CA1 pyramidal layer) and can be reset by

Received March 29, 2004; revised Aug. 4, 2004; accepted Aug. 6, 2004.

This work was supported by the Wellcome Trust and the Medical Research Council. We thank Stephen Burton, Charles King, and John Huxter for helpful discussions and contributions and Jim Donnett, David Edwards, and Clive Parker for technical assistance.

Correspondence should be addressed to Francesca Cacucci, Department of Anatomy and Developmental Biology, University College London, WC1E 6BT, London, UK. E-mail: f.cacucci@ucl.ac.uk.

DOI:10.1523/JNEUROSCI.2635-04.2004

Copyright $\odot 2004$ Society for Neuroscience $\quad$ 0270-6474/04/248265-13\$15.00/0 sensory and motor events (Buzsaki, 2002); theta phase can influence long-term plasticity (Hasselmo et al., 2002; Hyman et al., 2003), and the firing of hippocampal place cells as the animal moves through the place field shows theta phase precession across successive theta cycles (O'Keefe and Recce, 1993). In humans, theta episodes correlate with spatial maze-solving difficulty (Caplan et al., 2001).

We report on a category of cells recorded from the presubiculum and parasubiculum of the rat, termed theta-modulated place-by-direction (TPD) cells, which carry both location and orientation information. In addition, their firing pattern shows a marked rhythmicity at $7-10 \mathrm{~Hz}$ (in the theta frequency range) and is phase locked to the trough of the locally recorded theta wave. Although previous studies of the presubiculum and parasubiculum occasionally noted cells that might have been TPD cells (Taube et al., 1990a; Sharp and Green, 1994; Taube, 1995a; Sharp, 1996), the present study provides the first detailed characterization of this class of cells.

To investigate the role that TPD cells might have within the hippocampal spatial navigation system, we compared their spatial properties with those of place and head-direction cells. TPD firing was also examined while the rats foraged in different environments. The locational signal of a given TPD cell is environment specific, whereas its preferred direction is environment invariant. The directional signal appears to have a higher information content. We speculate that TPD cells mediate the integration of directional information into a theta-modulated navigational network.

\section{Materials and Methods}

Subjects

Fourteen male hooded Lister rats, weighing 280-400 gm at time of surgery, were used as subjects. They were maintained on a $12 \mathrm{hr}$ light/dark 
schedule (lights off at 3:00 P.M.). After surgery, they were placed on a food deprivation schedule to initially reduce their weight to $90 \%$ and then allow weight gain of $3 \mathrm{gm} /$ week.

\section{Surgery and electrodes}

Rats under deep anesthesia were chronically implanted with microdrives, using a mixture of isoflurane $(0.5-1.2 \%)$, nitrous oxide $(3.01 / \mathrm{min})$, and oxygen $(1.5 \mathrm{l} / \mathrm{min})$. Microdrives were attached to the skull with dental cement and stainless steel skull screws, which allowed the electrode tips to be vertically advanced through the tissue after surgery.

Details of surgical procedure are provided by Jeffery and O'Keefe (1999). Microelectrodes were constructed from HM-L-coated $90 \%$ platinum-10\% iridium wire, of 17 and $25 \mu \mathrm{m}$ diameters (California Fine Wire, Grover Beach, CA). Microelectrode bundles consisted of one of the following: four stereotrodes $(n=1)$ or two $(n=4)$, four $(n=8)$, or eight $(n=1)$ tetrodes. Microelectrodes were aimed at the dorsal presubiculum and parasubiculum $(6.7-7.6 \mathrm{~mm}$ posterior and $3.0-3.6 \mathrm{~mm}$ lateral to bregma). In one case (rat $G$ ), microelectrodes were aimed at the dorsal hippocampus (3.8 $\mathrm{mm}$ posterior and 2.4 lateral to bregma) (Paxinos and Watson, 1986). After completion of the experiments, the rats were killed with an overdose of sodium pentobarbital (Lethobarb; $10 \mathrm{mg}$ ) and perfused transcardially with saline, followed by $4 \%$ paraformaldehyde. The brain was sliced coronally into $40-\mu \mathrm{m}$-thick sections, which were mounted and cresyl violet Nissl-stained to aid visualization of the electrode track and tip.

\section{Single-unit recording}

Rats were allowed a 1 week postoperative recovery, after which microelectrodes were advanced ventrally by $25-50 \mu \mathrm{m} / \mathrm{d}$. When TPD or HD cells were found, recording sessions began. The electrode wires were AC-coupled to unity-gain buffer amplifiers. Lightweight hearing aid wires $(2-3 \mathrm{~m})$ connected these to a preamplifier (gain of 1000) and then to the filters and amplifiers of the recording system (Axona, St. Albans, UK). Signals were amplified $(15,000-50,000)$ and bandpass filtered (500 $\mathrm{Hz}$ to $7 \mathrm{kHz}$ ). Each of the channels of a given tetrode or stereotrode was recorded differentially with respect to a channel on another tetrode or stereotrode. Cluster cutting (isolating single units from the multiunit recording data) was performed manually using custom-made software (TINT; Axona).

Two small, infrared light-emitting diodes (LEDs), one brighter than the other, were attached to the rat's head for the purpose of tracking head position and orientation with a video camera and position-detection hardware (position sampling rate, $50 \mathrm{~Hz}$ ). The two LEDs were separated by $5-7 \mathrm{~cm}$ and identified on the basis of their differential brightness. Given a pixel size of $2.4 \mathrm{~mm}^{2}$ and a distance between the two lights of minimum $5 \mathrm{~cm}$, the minimum angle that could be resolved was $9^{\circ}$. The locational accuracy was $4.1 \mathrm{~mm}$.

\section{Spike waveform acquisition and analysis}

Each channel was continuously monitored at a sampling rate of $50 \mathrm{kHz}$, and action potentials were stored as 50 points per channel ( $1 \mathrm{msec} ; 200$ $\mu$ sec prethreshold; $800 \mu$ sec postthreshold) whenever the signal from any of the prespecified recording channels exceeded a given threshold set by the experimenter. For each cell isolated, an average waveform was constructed, and the following two parameters were measured: (1) the difference between the maximum (peak) and minimum (trough) voltages (peak-to-trough amplitude) and (2) the time between the peak and the trough.

\section{EEG acquisition and phase fitting}

The EEG signal was bandpass filtered at $0.34-125 \mathrm{~Hz}$ and sampled at 250 $\mathrm{Hz}$. Half-sinusoids in the theta frequency range $(6-16 \mathrm{~Hz})$ were aligned to negative-going deflections in the EEG record and the goodness-of-fit used to detect the presence of theta. Phase values from 0 to 359 were assigned to the EEG samples between successive zero crossings associated with good theta fits (O'Keefe and Recce, 1993; Huxter et al., 2003). The firing phase of each action potential was taken as the phase of the concurrent EEG sample. All of the spikes for which theta could not be fit were discarded from this analysis. Only cells for which at least $50 \%$ of the total number of spikes fired had a theta phase assigned were included in the phase preference analysis.

Details of cells used for comparison of theta rhythmicity (see Fig. 7D) are as follows: place cells $(n=17)$ were recorded from CA1 pyramidal layer of the hippocampus, and TPD cells $(n=30)$ and HD cells $(n=14)$ were recorded as described. "Theta $\mathrm{Hpc}$ " refers to presumptive interneurons (or "theta cells"; $n=10$ ) recorded in and around the CA1 pyramidal layer of the hippocampus, selected on the basis of narrow waveform shape and high mean firing rate. For these cell types, theta was locally recorded. Columns labeled "Types $1 \mathrm{~A}-1 \mathrm{C}, 2,3$ " $(n=10,29,26$, 7, and 41 , respectively) were recorded from the medial septum and the diagonal band of Broca, taken from and characterized according to the study by King et al. (1998). For these cell types, spikes were referenced to theta in the hippocampal fissure.

\section{Theta modulation index}

Temporal autocorrelograms were constructed by summing the number of times in which a spike occurred within each $5 \mathrm{msec}$ bin from 0 to 500 msec, given the occurrence of a spike at time 0 . These sums were then divided by the total time (total trial length) to yield the rate of occurrence for each interval. Temporal modulation of firing in the range $7-10 \mathrm{~Hz}$ was then assessed using a theta modulation index (TMI). The TMI was computed as the difference between the theta modulation trough (defined as mean of autocorrelogram bins, 50-70 msec) and the theta modulation peak (mean of autocorrelogram bins, 100-140 msec) over their sum.

\section{Behavioral testing}

Experiments were conducted in a black-curtained, circular testing arena $2.3 \mathrm{~m}$ in diameter. Between trials, rats were kept on a holding platform outside the arena. Two identical circular-walled (diameter, $78 \mathrm{~cm}$ ) and two identical square-walled (sides, $59 \mathrm{~cm}$ ), smooth, light-gray wooden boxes (all $50 \mathrm{~cm}$ high) were used, placed on a black, circular platform 90 $\mathrm{cm}$ in diameter, raised $27 \mathrm{~cm}$ above the floor. This platform was cleaned before every trial. The center of each box and the black platform always had the same location in the arena. An external cue card (102 cm high; 77 $\mathrm{cm}$ wide) suspended $25 \mathrm{~cm}$ inside the black-curtain rail provided directional constancy. The animals were carried along the same path between the environments, always facing the direction of travel, so that they were never purposefully disoriented. During trials, the rat searched for grains of sweetened rice randomly thrown into the environment.

\section{Firing-rate maps}

Locational maps. Position data were sorted into $4.7 \times 4.7 \mathrm{~cm}$ bins. For a given cell, firing rates in each bin were calculated by dividing the total number of action potentials during occupancy of the bin by the total duration of occupancy. The firing rate in each bin was smoothed using a $3 \times 3$ kernel, meaning that the firing rate for each bin was calculated as the average of the $3 \times 3$ bin square centered on that bin. [The bin size 4.7 $\mathrm{cm}$ is larger than usual for place-cell recording and was used because the maximum likelihood model (MLM) correction algorithm (see below) required a certain amount of sampling in each bin to work.] The five colors of firing-rate maps were autoscaled to represent $20 \%$ of the peak rate (red to dark blue). Unvisited bins are shown in white.

Directional maps. The directional firing characteristics of both HD and TPD cells are displayed as polar plots. The directional half-height range $\left(0-360^{\circ}\right)$ is subdivided into 60 bins of $6^{\circ}$ each. The number of spikes that the cell fired when the animal was facing its head in a specific direction is divided by the time spent facing that direction. No smoothing has been applied. The preferred direction of a cell is the direction at which firing rate is maximal. As a measure of the directional tuning, the directional half-height range is calculated as the extent of arc over which firing is more than or equal to one-half of the maximal firing rate.

\section{Criteria for data inclusion}

Cells were selected on the basis of their locational and directional correlates, rhythmicity of their firing, and spike isolation.

For a cell to be classified as an HD cell, it had to (1) have a peak rate in the directional field exceeding $1 \mathrm{~Hz}$ and (2) show no theta frequency modulation in the autocorrelogram. The second criterion follows from Sharp's (1996) study of postsubicular cells, in which none of the cells 
classified, using regression analysis in the HD category, showed any theta modulation.

For a cell to be classified as TPD, it had to meet the following criteria: (1) peak rate in the locational field exceeding $1 \mathrm{~Hz}$, (2) peak rate in the directional field exceeding $1 \mathrm{~Hz}$, and (3) clear theta modulation in the autocorrelogram. In addition, the cell had to be well isolated, with a 2 msec refractory period in its autocorrelogram. During the sessions in which at least one TPD cell was present, 55 cells were recorded that did not meet the above criteria for HD or TPD. Of these, 11 matched all of the TPD criteria outlined above, except for spike isolation. Of the others, 17 showed theta modulation (mean firing rate, $5.0 \mathrm{~Hz}$; range, $0.5-21.9 \mathrm{~Hz}$ ), ranging from mild to strong, and the remaining 27 showed no theta rhythmicity at all (mean firing rate, $2.6 \mathrm{~Hz}$; range, $0.3-19.6 \mathrm{~Hz}$ ). For these 44 cells, no obvious behavioral correlate could be seen.

CA1 PCs were taken from Lever et al. (2002a) and Wills et al. (2004) and had to show a peak rate in the locational field exceeding $1 \mathrm{~Hz}$.

\section{Sampling bias}

The firing of TPD cells appears to be modulated by both the animal's position and head direction, but, as a result of inhomogeneous sampling of positions and head directions, the relative contribution of these two behavioral variables to TPD cell firing is difficult to judge. As has been observed previously (Muller et al., 1994), sampling biases might cause place cells to show an apparent directional modulation of their firing rates, and, conversely, the firing of head-direction cells sometimes appears to be modulated by the location the animal occupies. For example, a head-direction cell with a preferred northeast direction might show a place field against the northeast portion of the wall of the cylinder solely attributable to the fact that whenever the rat is in the northeast region of the cylinder, it will often face northeast and cannot face southwest (because of the physical constraints that the rat body poses) (see Figs. $4 C$, $5 A$ ). Conversely, for place cells, a spurious head-direction response might arise if the animal samples some head directions more frequently (for instance, if that place field is near a wall) (see Fig. $4 A$ ). We deal with this problem in two ways, as detailed below.

\section{Distributive hypothesis and MLM analyses}

To deal with the problems of sampling bias, the following two analytical procedures were used: the "distributive hypothesis" method (Muller et al., 1994) and the MLM procedure (N. Burgess, F. Cacucci, C. Lever, and J. O'Keefe, unpublished data).

The distributive hypothesis procedure was introduced to quantify the influence of head direction on the firing of place cells. The approach consists of calculating the directional firing that one would predict under the null hypothesis that place-cell firing is only modulated by location and that the only influence of head direction arises from the sampling bias discussed above. The predicted rate as a function of direction is as follows:

$$
R_{\text {Pred }}(\theta)=\Sigma\left(R_{\mathrm{P}} T_{\mathrm{P}}(\theta)\right) / \Sigma T_{\mathrm{P}}(\theta),
$$

where $R_{\mathrm{P}}$ is the firing rate in one pixel and $T_{\mathrm{P}}(\theta)$ is the time spent facing head-direction $\theta$ in that pixel. One then tests whether the observed directional tuning for the cell, $R_{\mathrm{Obs}}(\theta)$, differs from the one calculated under the assumption that the effect of direction is purely artifactual, $R_{\text {Pred }}(\theta)$. This is done by computing a "distributive ratio" (DR) as follows:

$$
\mathrm{DR}=\Sigma \mid \ln \left(\left(1+R_{\mathrm{Obs}}(\theta)\right) /\left(1+R_{\mathrm{Pred}}(\theta)\right) \mid / N,\right.
$$

where $N$ is the number of directional bins considered. For a perfect prediction, DR is zero. A perfect prediction indicates that the null hypothesis is true, namely place-cell firing is only modulated by location and the directional influence on place-cell firing is only attributable to the inhomogeneity of sampling referred to above, whereas high values of this ratio would indicate a poor prediction (indicating that head direction accounts for some of the variability in the firing rate of the cell).

Muller et al. (1994) successfully showed that directional correlates of place cells firing in cylindrical environments are artifactual and suggested that the same algorithm might be applied to head-direction cells by swapping the place and direction terms. The only modification to the Muller et al. (1994) method adopted here is that predicted firing rates were calculated over all visited bins rather than only those within the place field. This was done because the background firing rate of thetamodulated place-by-direction cells is much higher than that of place cells and therefore cannot be assumed to be zero.

Although this analysis can show whether a modulation of firing is artifactual or not, it cannot correct for any artifacts detected. For this purpose, a new analysis was developed (MLM; our unpublished observations). The expected number of spikes per location and direction bin is modeled as the product of independent functions of the rat's location $\left(p_{i}\right)$ and direction $\left(d_{j}\right)$ given the dwell time $\left(t_{i j}\right)$ at each location and direction, as follows:

$$
E\left(n_{i j}\right)=p_{i} d_{j} t_{i j}
$$

It is assumed that the probability distribution of the observed data follows a Poisson distribution. Thus, the likelihood of finding $n_{i j}$ spikes in bin $i j$ is as follows:

$$
p\left(n_{i j} \mid p_{i}, d_{j}, t_{i j}\right)=\left(\lambda_{i j}\right)^{n_{i j}} \exp \left(-\lambda_{i j}\right) / n_{i j} !,
$$

where $\lambda_{i j}=p_{i} d_{j} t_{i j}$. The values of $p_{i}$ and $d_{i}$ that maximize the likelihood of the data $n_{i j}$, given the model, obey the following:

$$
\begin{aligned}
p_{i} & =\frac{\left\langle n_{i j}\right\rangle_{j}}{\left\langle d_{j} t_{i j}\right\rangle_{j}}, \\
d_{i} & =\frac{\left\langle n_{i j}\right\rangle_{i}}{\left\langle p_{i} t_{i j}\right\rangle_{i}},
\end{aligned}
$$

where $\langle.\rangle_{m}$ denotes the average over index $m$. These equations are iterated to find $p_{i}$ and $d_{j}$. The values are then scaled to match the total number of spikes recorded, and the "corrected" locational maps and directional plots are displayed.

Both analyses were applied to directional and locational data of the PC $(n=46)$, TPD $(n=46)$, and HD $(n=46)$ cell samples. The data were collected from $8 \mathrm{~min}$ recording trials in the standard cylinder. The particular trial chosen was that in which the cell fired the greatest number of spikes.

\section{Spatial analysis}

The following six spatial measures were computed to quantify the spatiality of TPD cell firing and to compare it with that of PCs and HD cells (in both the uncorrected and MLM conditions): locational and directional selectivity, locational and directional information, place-field size, and directional half-height range. Locational and directional selectivity were calculated as the ratio between the locational (directional) peak firing rate and the overall mean firing rate for that cell. Preferred direction refers to the bin with the highest rate of directional firing. Locational field peak refers to the bin with the highest rate of locational firing. Locational field size was defined as the number of bins in which firing was higher than one-half of the peak rate and expressed as a percentage of the total number of visited bins. These bins did not need to be contiguous, because this would make it difficult to compare across cell types (for example, it is not uncommon for HD cells to show multiple locational fields). The directional half-height range is expressed in degrees and is calculated as the extent of the arc in which firing is more than or equal to one-half of the maximal firing rate. Information content was computed for both the place and directional components of the firing of the cells, using the spatial information measure introduced by Skaggs et al. (1993), and quantifies the amount of spatial information (locational or directional) carried by each spike (expressed in bits per spike).

\section{Correlation analysis}

Locational firing of 38 TPD cells was compared across recording sessions performed in (1) the same environments, to assess the stability of the firing, and (2) three different environments (cylinder, square, and open platform). A bin-by-bin correlation analysis was applied to the smoothed firing-rate maps obtained under these conditions (cylinder maps contain an average of 900 bins each) (Jeffery et al., 2003). Bins in which the rate was zero in both maps were discarded. The resulting $r$ values served as an 
index of the similarity of locational firing across the environments used. To compare firing patterns across the cylinder and the square, it is necessary to topologically transform the data. The details of the topological transformation algorithm were given previously (Lever et al., 2002a), the only difference being that, in this case, square and circular platform data were transformed into cylinder data, not vice versa. Two scaling factors were applied to match the size of the transformed maps to that of the cylinder: 1.06 for the square-to-cylinder and 0.77 for the open platformto-cylinder transformations. These scaling values were derived experimentally by calculating the ratio between the average radius of the topologically transformed map and the cylinder map across several trials. To give a greater spatial resolution, correlation analyses were performed on data that had been binned using $2.3 \mathrm{~cm}$ bins and smoothed using a $5 \times 5$ kernel. Trials were selected as follows: the cylinder trial, in which the cell fired the highest number of spikes, was chosen (baseline cylinder) along with the temporally closest trials in the square, open platform, and the second cylinder. Locational firing patterns in the baseline cylinder were then compared with all of the other conditions (transformed square, transformed open platform, and second cylinder) using the bin-by-bin correlation procedure. The ANOVAs were performed on the $r$ values both before and after a Fisher Z transform. Only the results of the ANOVAs on untransformed $r$ values are presented, because no difference was observed between the transformed and untransformed conditions.

\section{Results}

\section{Nomenclature}

In total, 46 TPD and 63 HDs were recorded, from 7 and 10 rats, respectively. In three animals, both TPD and HD cells were recorded, sometimes simultaneously. In addition, 46 PCs were added to the dataset to compare the spatial characteristics of TPD cells with those of PCs and HD cells.

Throughout this paper, cells will be identified by the class, followed by a letter and a number. The letter indicates the animal, and the number indicates the cell (in temporal order). For example, cell TPD b4 is the fourth TPD cell recorded from animal b, and cell HD $\mathrm{f} 2$ is the second HD cell recorded from animal $\mathrm{f}$.

Cells were assigned to each category according to the criteria listed in Materials and Methods. Figure 1 illustrates that the three cell groups identified using our selection criteria are well segregated in a three-dimensional space, along the following independent parameters: (1) locational information, (2) directional information, and (3) degree of theta modulation. We performed a statistical analysis of the spatial and temporal characteristics of TPD cells firing to confirm the validity of our cell classifications.

\section{Spatial characteristics}

The firing rate of TPD cells appears to be a function of both location and head direction. Figure 2 shows five examples of theta-modulated place-by-direction cells. Cell TPD f3 (Fig. $2 A, B)$ fires whenever the animal is in the north-central region of the cylinder and is facing southwest (see central map in $A$ for locational field and polar plot in $B$ for directional preference). Also shown are eight locational firing-rate maps, each depicting cell firing restricted to a specific $45^{\circ}$ range of head directions. For example, the top map shows the locational firing pattern of the cell when the animal is facing north, the next map (clockwise) when the animal is facing northeast, etc. It is clear from these maps that firing is almost completely restricted to the central region of the cylinder and is strongly modulated by head direction. The peak firing rate of the cell when the rat is facing southwest (the preferred direction of the cell) is six times higher than that obtained when the animal is facing in the opposite direction. From Figure $2 \mathrm{~A}$, it is apparent that this effect cannot be attributed to lack of sampling of the region encompassing the locational field of the cell when the rat is facing northeast. Figure $2 C$

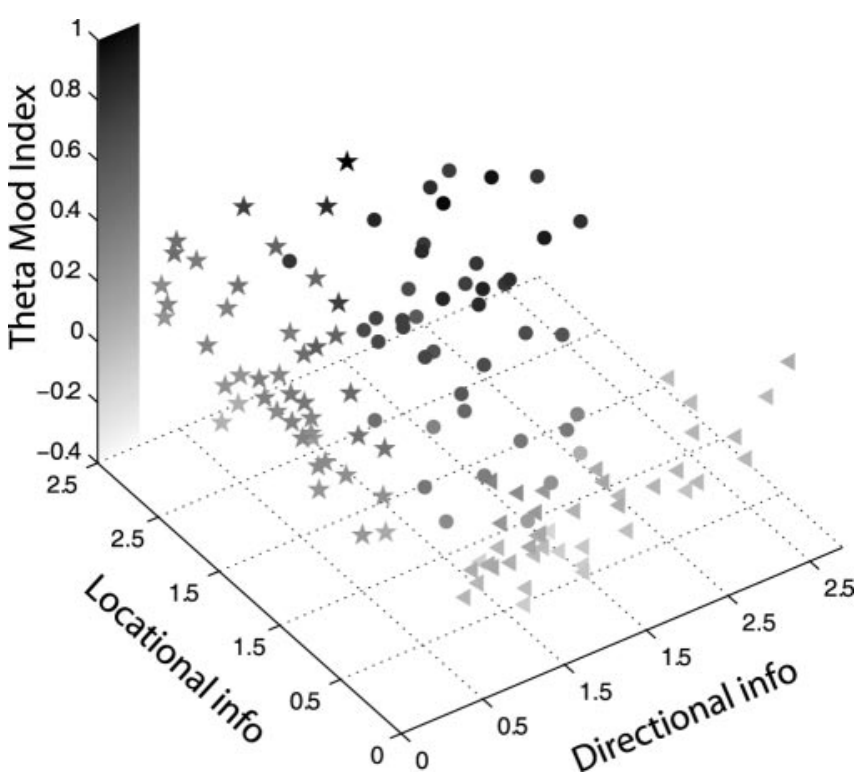

Figure 1. PCs (stars), TPD cells (circles), and HD cells (triangles) can be classified on the basis of their spatial and temporal firing characteristics: $x$-axis, locational information (corrected using MLM); $y$-axis, directional information (corrected using MLM); and z-axis, theta modulation index. The gray shade of each symbol indicates its position on the $z$-axis, shown by the grayscale indicator bar alongside the $z$-axis. The ranges and means for the three groups are as follows: locational information, PC, $0.37-2.32$, mean of 1.27 ; TPD, $0.10-1.30$, mean of 0.49 ; $H D, 0.04-0.98$, mean of 0.27 ; directional information, $P C, 0.04-0.59$, mean of 0.26 ; TPD, $0.10-1.54$, mean of $0.74 ; \mathrm{HD}, 0.45-2.82$, mean of 1.31 ; theta modulation, $\mathrm{PC},-0.05-0.96$, mean of 0.31 ; TPD, $0.07-1.00$, mean of $0.58 ; \mathrm{HD},-0.28-0.23$, mean of -0.06 .

shows four more examples of TPD cell locational and directional firing.

TPD firing is modulated by both location and head direction Is the apparent locational and directional modulation of TPD firing artifactual? That is, does it result from the sampling bias discussed in Materials and Methods? To assess this, we calculated distributive ratios (Muller et al., 1994) for both the locational and directional component of the firing of the cells for 46 TPD cells and compared them with those of 46 PCs and 46 HD cells. The locational firing-rate maps used contain an average of 245 visited bins, whereas the directional maps contain 60 bins (all visited).

As mentioned above, distributive ratios measure the goodness-of-fit between a predicted and an observed firing distribution. Departures from zero indicate that not all of the locational responses of the cell can be accounted for on the basis of inhomogeneous sampling (see Materials and Methods).

We would expect that place cells have low values of directional distributive ratio and high values of locational distributive ratio, and that HD cells have high values of directional distributive ratio and low values of locational distributive ratio. The values of TPD cells are expected to be intermediate between them, because both location and head direction have an influence on the firing of these cells. Thus, neither the locational nor the directional firing patterns of these cells can be fully predicted on the basis of the other spatial variable.

As predicted, the mean values for the locational distributive ratio were as follows: $0.41 \pm 0.02$ for place cells, $0.29 \pm 0.02$ for TPD cells, and $0.18 \pm 0.08$ for HD cells. The mean values for the directional distributive ratio were as follows: $0.15 \pm 0.05$ for place cells, $0.37 \pm 0.02$ for TPD cells, and $0.45 \pm 0.01$ for HD cells (Fig. $3 A$, bar graphs, mean $\pm \mathrm{SE}$ ). The value of the directional distributive ratio for place cells is similar to the one reported by Muller 


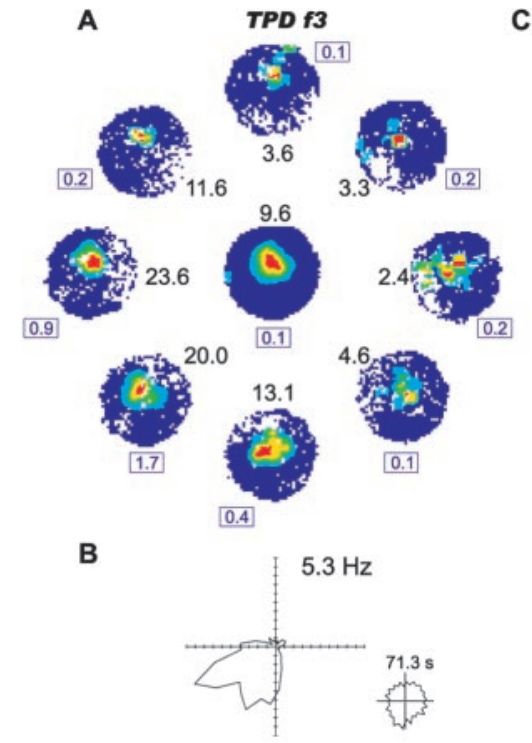

C

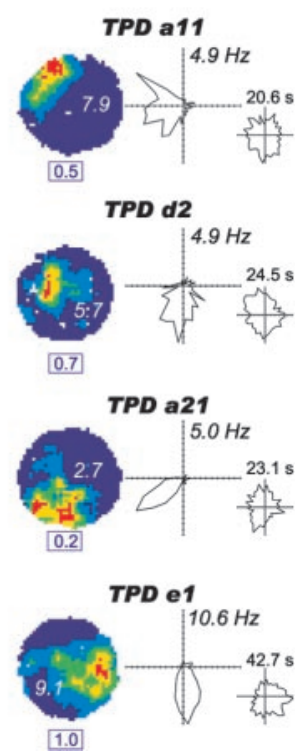

Figure 2. Firing of TPD cells is modulated by both location and head direction. $A$, Locational firing-rate maps for cell TPD f3. Central firing-rate map is direction independent. Surrounding rate maps show locational firing for specific head directions only (in $45^{\circ}$ bins). Black numbers refer to peak firing rate (in hertz), and blue numbers in blue boxes refer to the mean rate of the dark blue area of the map ( $0-20 \%$ of peak firing rate; in hertz). All maps are individually autoscaled. $B$, Directional polar plot showing that cell TPD $f 3$ fires maximally when the rat faces southwest. Number refers to peak firing rate. Bottom right, Directional dwell-time polar plot (in seconds). C, Locational and directional firing-rate maps of four representative TPD cells. Data refers to $8 \mathrm{~min}$ recording sessions, in the canonical cylindrical environment. For each cell, the locational firing-rate map (left; white number refers to peak firing rate; blue number is as in $A$; both in hertz) and the directional polar plot (right) are shown. The bottom right of each rate polar plot indicates the directional dwell-time polar plot (in seconds).

et al. (1994) for their sample of 16 place cells $(0.19 \pm 0.03)$, confirming the robustness of the finding. An ANOVA revealed that there was a significant effect of cell type on both the locational $\left(F_{(2,135)}=36.79 ; p<0.001\right)$ and directional $\left(F_{(2,135)}=\right.$ 91.79; $p<0.001)$ distributive ratios. Post hoc tests showed that, for both distributive ratios, all of the groups differed significantly from each other (Newman-Keuls; $p<0.01$ ). These results support the hypothesis that the firing of TPD cells is modulated by both the animal's location and head direction.

\section{Locational and directional influences on firing, corrected for sampling bias}

To assess the separate contributions of location and head direction to place, TPD, and HD cell firing, a new computational approach (MLM; see Materials and Methods) was applied to the data. In this approach, the firing rate of a cell is modeled as the product of independent functions of the rat's location and direction. The separate dependencies on location and direction are then estimated using a maximum likelihood approach (see Materials and Methods). This provides a way of taking into account potential artifacts introduced by the inhomogeneous sampling of the behavioral variables in question to the firing rates of the cells.

Figure 4 illustrates the effect the MLM algorithm has on both the locational and directional maps of two PCs, two TPD cells, and two HD cells. It can be seen that the firing of TPD cells reflects genuine influences of both direction and location, because both of these maps are only slightly altered by the MLM algorithm. In contrast, the directional influences in the uncorrected firing of place cells are probably artifactual, because the overall directional profile of each cell changes significantly when the MLM algo-

A
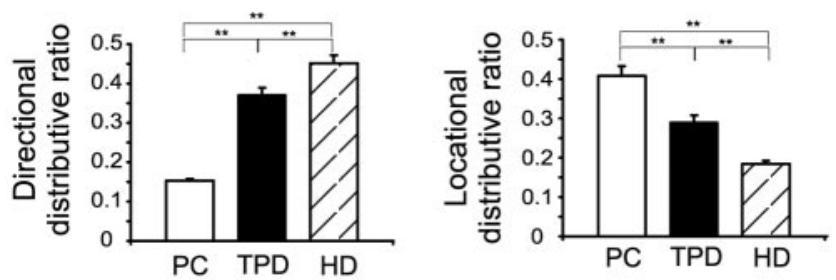

B
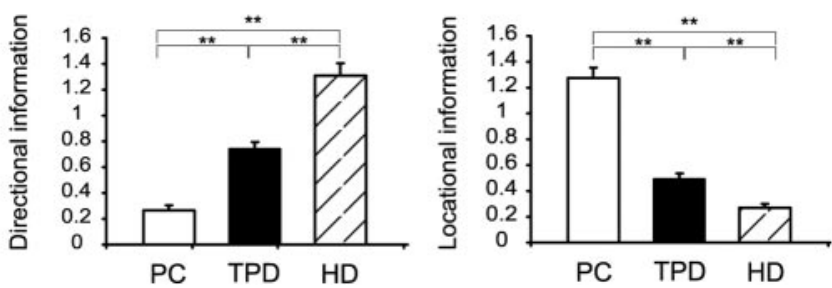

Figure 3. TPD firing is modulated by both location and direction. $A$, Mean \pm SE bar graphs for directional (left) and locational (right) distributive ratios across the three cell types. TPD locational and directional firing cannot be successfully predicted using the distributive hypothesis procedure, indicating that both variables have an influence on the firing of the cells. $B$, Mean \pm SE bar graphs for the corrected directional (left) and locational (right) information values across the three cell types. TPD cells have intermediate values of both locational and directional information to those of PC and HD cells. ${ }^{* *} p<0.01$ indicates significant difference between groups.

rithm is applied. Similarly, the locational fields of HD cells are significantly altered by the MLM algorithm. Note that, in contrast, the locational fields of PCs and the directional fields of HD cells are almost unchanged by the correction.

Figure 5 shows the effect of the MLM correction on the position of the peaks of the locational fields for PCs, TPD cells, and HD cells, expressed as a proportion of the distance from the center to the edge of the cylinder. Figure $5 \mathrm{~A}$ shows the data for the uncorrected condition, demonstrating that the locational field peaks of PCs and TPD cells are mildly skewed toward the edge of the cylinder. In contrast, the distribution of locational field peaks of HD cells is sharply concentrated at the edge. This suggests that the locational fields of HD cells are artifactual, because sampling of direction is most inhomogeneous at environmental boundaries (for a more detailed explanation, see Materials and Methods, Sampling bias). Applying the MLM correction (Fig. 5B) dramatically changes the distribution of peaks for HD cells, whereas it leaves those of TPD cells and PCs relatively unchanged. This further suggests the robustness of the TPD locational firing and suggests instead that HD locational fields are products of the kind of sampling bias discussed in Materials and Methods.

We compared the corrected firing properties of TPD cells with HD cells and PCs, across a group of spatial measures. The cell samples are identical to those used for the distributive hypothesis procedure. A multivariate ANOVA, with cell type as the between-subject factor, was performed on the six measures of spatial selectivity considered. The overall multivariate analysis for cell type $\left(F_{(21,132)}=\right.$ $14.19 ; p<0.001$ ) was significant, allowing for inspection of all univariate ANOVAs for the six dependent variables using post hoc Newman-Keuls comparisons. Table 1 shows the mean \pm SEs for each spatial measure considered and the results of the statistical analysis (for the same analysis on uncorrected data, see supplemental material, available at www.jneurosci.org).

TPD values for each of the spatial variables analyzed are inter- 
Locational Uncorr Locational MLM Directional Uncorr Directional MLM

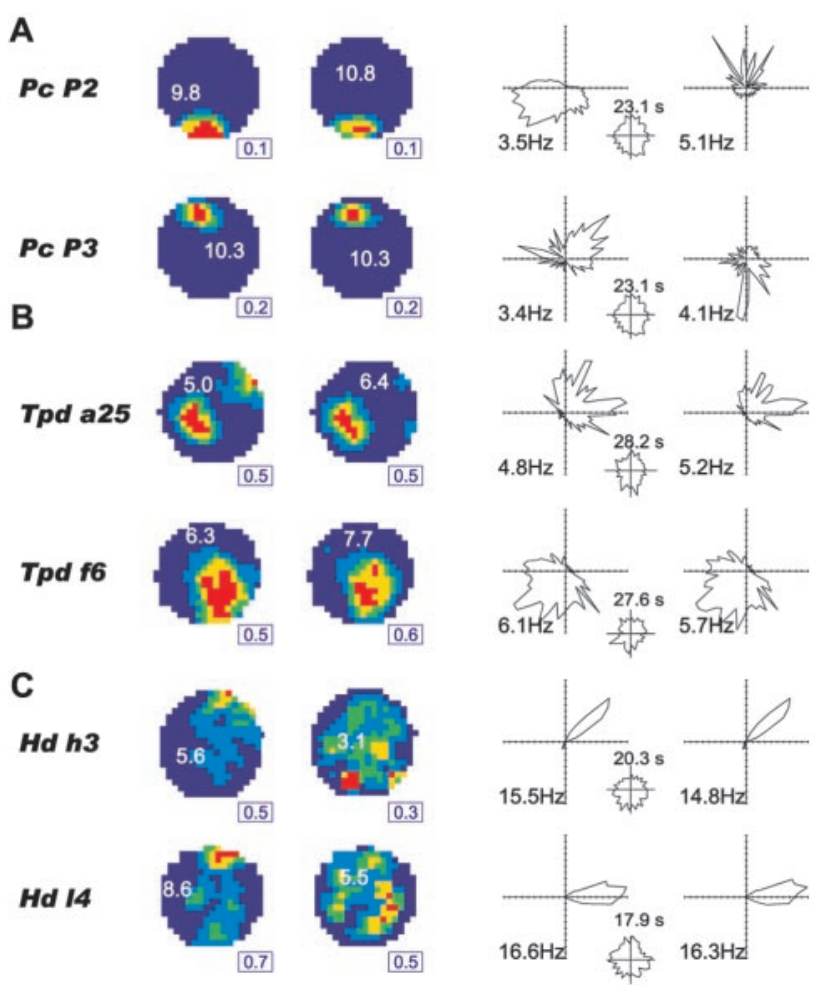

Figure 4. Effects of the MLM correction on the locational and directional firing of two PCs $(A)$, two TPD cells $(B)$, and two HD cells ( $(C$. Locational firing-rate maps are shown in the left two columns, and directional polar plots are shown in the right two columns. In each category of locational and directional firing, the left column shows uncorrected (Uncorr) plots, and the right column (MLM) shows plots calculated by applying the MLM correction algorithm (see Materials and Methods). Numbers in white in the locational maps and in black at the bottom left corner of the polar plots refer to peak firing rate (in hertz). Numbers in blue are as in Figure 2. Small dwell-time polar plots (bottom right of rate polar plots) are as in Figure 2. Mean correlation $r$ values between uncorrected and MLM corrected maps are as follows: location, HD, 0.48; TPD, $0.72 ; \mathrm{PC}, 0.96$; direction, HD, 0.99; TPD, 0.95; PC, 0.74. Despite the ceiling effect of the directional $r$ values, it can be seen that $\mathrm{PCs}$ show a robust locational effect (i.e., undiminished by MLM), HD cells show a robust directional effect, and TPD cells show both.
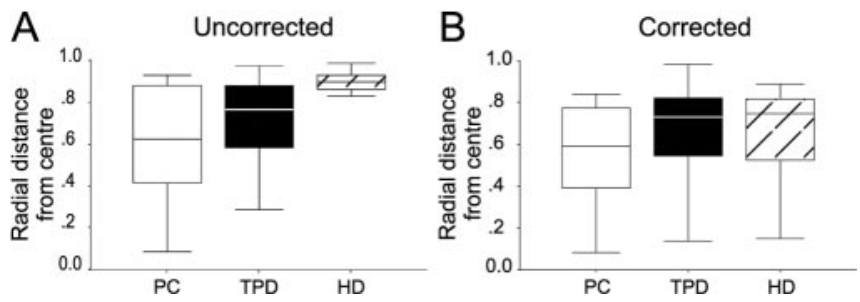

Figure 5. The locational fields of HD cells, but not TPD cells or PCs, are artifactual. Boxplots showing the distribution of locational field peaks in the cylinder for each cell group (PC in white; TPD in black; HD with diagonal stripes), before $(A)$ and after $(B)$ applying the MLM correction. On the $y$-axis, the radial distance from the center of the locational peaks is expressed as a proportion (center, 0 ; edge, 1). Note the large change in location for HD cells. The box represents the interquartile range. The whiskers are lines that extend from the box to the highest and lowest values, excluding outliers. A line across the box indicates the median.

mediate between those of PCs and HD cells. In particular, as expected, PCs have values associated with the highest locational specificity, HD cells have the lowest, and TPD cells have intermediate values, somewhat closer to those of HD cells. A similar pattern is seen across the directional measures, for which HD cells have the highest values, PCs have the lowest, and TPD cells have intermediate (Fig. 3B, mean \pm SE bar graphs of locational and directional information).

These results confirm and extend those obtained by the distributive hypothesis procedures; the firing of TPD cells is modulated by both the animal's location and head direction. Locational and directional firing of TPD cells is robust, given that the MLM correction does not eliminate the contribution of either variable to the firing of the cells, whereas it severely decreases the contribution of head direction to the firing of PCs and of location on HD firing (Fig. 4).

We next attempted to compare the strengths of the locational and directional influences on TPD cell firing using information measures. However, these measures are sensitive to bin number, so the most appropriate comparison is one in which the bin numbers for both spatial measures are equivalent. Accordingly, the data were divided into approximately equivalent numbers of bins (70 and 64 bins of size $9.4 \mathrm{~cm}^{2}$ and $5.6^{\circ}$, respectively, with no smoothing applied). The directional information values of TPD cells were larger than the locational ones (corrected values, mean \pm SE; locational, $0.58 \pm 0.05$; directional, $0.75 \pm 0.06)$. A pairwise $t$ test confirms that these values are significantly different ( $\mathrm{df}=44 ; t=-2.5 ; p<0.025)$. It thus appears that, on average, TPD cells carry slightly more directional than locational information.

\section{Waveform analysis}

For each of the TPD and HD cells recorded, the averaged waveforms of all of the spikes recorded during an $8 \mathrm{~min}$ trial in the standard cylindrical enclosure (see Materials and Methods) were constructed. The largest spike appearing on the stereotrode-tetrode was selected for each TPD and HD cell. The spike height (peak-to-trough voltage) and the spike width (time between the peak and the trough) were calculated for both TPD and HD cells (bandpass filtering between $500 \mathrm{~Hz}$ and $7 \mathrm{kHz}$ ). For examples of waveforms from each cell type, see Figure 6. The average spike height for TPD and HD cells is $125.24 \pm 4.7$ and $143.66 \pm 5.7 \mu \mathrm{V}$, respectively. A two-tailed $t$ test revealed that the mean spike height of TPD cells is significantly different from that of HD cells ( $\mathrm{df}=105 ; t=-2.4 ; p<0.025)$. The average spike width is $205.87 \pm 15.3 \mu \mathrm{sec}$ for TPD cells and 360.49 $\pm 14.3 \mu \mathrm{sec}$ for HD cells. Again, there is a significant difference between these values ( $\mathrm{df}=105 ; t=-7.3 ; p<0.001$ ). Thus, TPD cells have spikes of lower amplitude and shorter duration than those of HD cells. In most cases, waveforms of TPD cells also show a narrow latepositive potential (TPD, a11, a18, f3), whereas HD cells usually show a broad late-positive potential, similar to that of CA1 pyramidal cells (HD, j15, k12, h4). For HD cells, a pattern emerged whereby cells recorded from any given animal showed narrow waveforms earlier on, whereas cells recorded later tended to show pyramidal-like waveforms (the direction of electrode penetration ran from white matter to deep, to superficial layers of presubiculum and parasubiculum). No such pattern was observed for TPD cells.

\section{Theta modulation of TPD firing}

Theta-modulated place-by-direction cell firing shows a marked rhythmicity at $\sim 7-10 \mathrm{~Hz}$. Figure $7 A$ shows a representative $3 \mathrm{sec}$ EEG trace, along with the simultaneously recorded action potentials of one TPD cell. TPD spikes have a strong modulation by theta occurring around the trough of the locally recorded theta oscillation. 
Table 1. Statistical analysis of the spatial properties of TPD cells

\begin{tabular}{|c|c|c|c|c|c|}
\hline & $\mathrm{PCs}$ & TPD & HD & $F_{\text {value }}^{* * *}$ & SNK \\
\hline \multicolumn{6}{|l|}{ Locational measures (corrected) } \\
\hline Locational selectivity & $7.44 \pm 0.48$ & $4.57 \pm 0.40$ & $3.41 \pm 0.28$ & 27.43 & $1,{ }^{* *} 2_{1}^{* *} 3^{*}$ \\
\hline Information (bits per spike) & $1.27 \pm 0.08$ & $0.49 \pm 0.05$ & $0.27 \pm 0.03$ & 83.85 & $1,{ }^{* *} 2_{1}^{* *} 3^{* *}$ \\
\hline Field size & $10 \pm 6 \%$ & $15 \pm 2 \%$ & $25 \pm 3 \%$ & 11.10 & $2,{ }^{* *} 3^{* *}$ \\
\hline \multicolumn{6}{|l|}{ Directional measures (corrected) } \\
\hline Directional selectivity & $2.87 \pm 0.20$ & $4.43 \pm 0.24$ & $6.91 \pm 0.41$ & 47.68 & $1,{ }^{* *} 2_{1}^{* *} 3^{* *}$ \\
\hline Information (bits per spike) & $0.26 \pm 0.04$ & $0.74 \pm 0.06$ & $1.31 \pm 0.09$ & 62.01 & $1,{ }^{* *} 2,{ }^{* *} 3^{* *}$ \\
\hline Half-height directional range & $105 \pm 11^{\circ}$ & $66 \pm 5^{\circ}$ & $43 \pm 3^{\circ}$ & 18.42 & $1,{ }^{*}{ }_{1}^{* *} 3^{*}$ \\
\hline
\end{tabular}

For each set of locational and directional measures, the values and significant differences between groups are reported (values are corrected using the MLM). For details of the spatial measures, see Materials and Methods. Information is given in bits per spike. Cell numbers are as follows: 44PC, 44 TPD, and 43 HD (for locational measures) and $46 \mathrm{PC}, 43 \mathrm{TPD}$, and $45 \mathrm{HD}$ (for directional measures). Numbers are not the same across variables because sometimes the MLM procedure did not converge. 1, PC versus TPD; 2 , PC versus HD; 3 , TPD versus HD. SNK, Student-Newman-Keuls test. ${ }^{*} p<0.05 ;{ }^{* *} p<0.01 ;{ }^{* * *} p<0.001$.
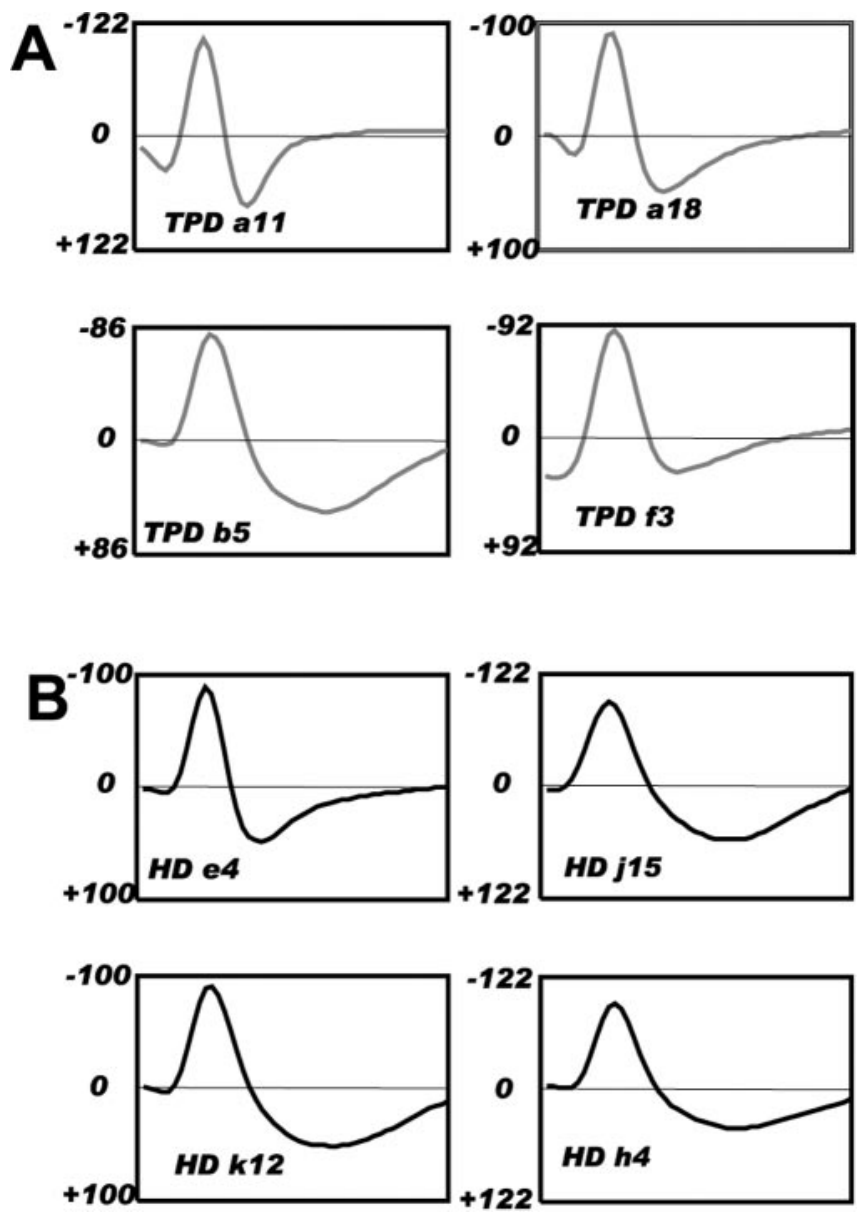

Figure 6. Representative waveforms of four TPD $(A)$ and four HD $(B)$ cells. The $y$-axis scale denotes microvolts (negative up), and the horizontal line through 0 denotes the resting or baseline potential. The length of the $x$-axis represents 1 msec. The waveforms of most TPD cells show a short late-positive potential (see TPD a11, a18, f3, and HD e4), whereas those of HD cells are mostly pyramidal-like, with a long positive potential (see HD k12, j15, h4, and TPD b5).

\section{Degree of modulation by theta}

Autocorrelation histograms of three representative TPD cells are shown in Figure $7 B$. These indicate the depth and frequency of theta modulation (autocorrelograms of one HD cell and one PC are shown for comparison). It can be seen that the TPD cells are highly modulated at the theta frequency. Autocorrelation histograms were used to quantify the degree of theta modulation (theta modulation index; see Materials and Methods) for all of the cells of each cell type (TPD, HD, and PC). The mean theta modulation index was $0.31 \pm 0.03$ for PCs, $-0.06 \pm 0.02$ for $\mathrm{HD}$ cells, and $0.58 \pm 0.03$ for TPD cells (Fig. 1 ).
For those cells for which a local EEG could be recorded (17 PCs, 30 TPD cells, and 14 HD cells), a more detailed analysis was performed, based on the timing of spikes relative to the phase of the EEG oscillation. Several trials were combined for each cell, to increase the number of spikes included in the analysis. No difference was found in either theta modulation or theta preference across trials.

A theta phase value was assigned to each spike that occurred during EEG epochs showing clear theta (at least $50 \%$ of the spikes the cell fired during the trials considered; see Materials and Methods). Theta phase distributions for each cell were tested for uniformity, using the Rayleigh test. For each TPD cell and PC tested, spikes did not occur randomly at all of the theta phases $(p<0.001)$. For HD cells, the hypothesis of uniform distribution of spikes could not be discarded ( $p>0.1$ ), showing that HD firing is not modulated by theta, as in line with our selection criteria. This was also true of HD cells recorded simultaneously with TPD cells (Fig. $7 B, C$, cells TPD f5 and HD f6).

Examples of theta phase distributions for the three cell types are shown as circular histograms in Figure $7 C$. The theta phase distributions of TPD cells and PCs can be modeled as von Mises distributions, the equivalent of the normal distribution for circular data (Fisher, 1993). The mean phase angle and concentration parameter were computed for each cell.

We take the concentration measure as an index of the strength of theta modulation. This is because it is inversely related to the dispersion of the data (which is analogous to the variance in linear statistics) (Fisher, 1993) and thus indicates the degree of rhythmicity for each cell. High concentration values imply that the data are "peaked" around a particular theta phase value, indicating that cell firing is strongly modulated by theta; low concentration values indicate that theta modulation is quite loose.

TPD cells had the highest average value of concentration $(0.73 \pm 0.04)$, followed by PCs $(0.39 \pm 0.04)$ and HD cells $(0.10 \pm 0.02)$. A one-way ANOVA confirmed that the main effect of cell type on concentration was significant $\left(F_{(2,58)}=56.10 ; p<\right.$ 0.001 ), and Scheffe's post hoc tests revealed that each cell group was significantly different from each other $(p<0.01)$. This EEGrelated analysis confirms our selection criteria based on the shape of the autocorrelation histograms of the cells.

The concentration value of a cell does not depend on the number of spikes it fires $(r=0.001 ; p>0.1$, for the 61 cells), ruling out the possibility that the uneven number of spikes across cell type could contribute to the difference in concentration seen.

In Figure $7 D$, concentration values for PCs, TPD cells, and HD cells included in this study are shown together with those found in septal cells by King et al. (1998). The degree of theta modulation of TPD cells appears to be very similar to that of type Ia septal cells, and only type Ib cells show a deeper theta modulation than TPD cells.

\section{Theta phase preference}

As Figure $7 A$ suggests, TPD spikes tend to occur at the trough, or just before the trough, of the locally recorded theta oscillation. We plotted the mean values of theta phase for all of the PCs, TPD cells, and HD cells. Results are summarized in Figure 7E as circular histograms. A value of $90^{\circ}$ is conventionally assigned to the trough of the theta oscillation and of $270^{\circ}$ to its peak. 
TPD mean phase values are highly clustered around a mean of $79.50 \pm 6.17^{\circ}, \mathrm{PC}$ values are less tightly clustered around a mean of $193.92 \pm 14.41^{\circ}$, whereas the mean theta phase distribution of HD cells is highly dispersed, with a mean of $47.92 \pm$ 94.53 ${ }^{\circ}$. Only TPD and PC distributions are significantly clustered around their mean values (Rayleigh tests; $p<0.001$ ). These results indicate that TPD cell firing preferentially occurs just before the trough of the locally recorded theta oscillation.

Note that no direct comparison between the phase preference of TPD cells and PCs relative to each other is possible, given that these values refer to the locally recorded theta oscillations, and it is more than likely that theta recorded from such distant brain areas is not in phase.

PC phase preference is more variable than TPD. This possibly reflects the fact that PC phase preference is not fixed but precesses as the rat traverses the place field (O'Keefe and Recce, 1993). Although only a small range of data were inspected, no evidence of phase precession was observed for TPD cells (but note that it is more difficult to see phase shift in place cells in the open field). The rather small range of theta phase values for individual TPD cells (Fig. 7) further suggests that any degree of phase shift must be relatively minor if it occurs.

\section{Directional stability and constancy}

The activity of 34 TPD and 25 HD cells was recorded during two $8 \mathrm{~min}$ trials, in the cylinder, inside the curtained enclosure.

Before recording began, the animals were brought inside the curtained environment in a standard way, always facing north, and were placed in the middle of the cylindrical environment.

The mean absolute angular difference between the preferred directions in the two cylinder trials was $15.0 \pm 2.7^{\circ}$ for TPD cells and $11.6 \pm 2.1^{\circ}$ for HD cells (values are corrected using the MLM procedure). These values are not significantly different $(t=$ $-0.94 ; p>0.1$ ), showing that TPD directional signal stability is comparable with that of HD cells.

The experiment described below was designed to test whether the directionality of TPD cells is constant within and outside the curtained enclosure. Given that these two environments share very few sensory features, this is a way to assess whether the directional signal seen in TPD cells generalizes across environments (similar to HD cells) or if it is rather tuned to sensory features specific for each environment.

The activity of 13 TPD and 14 HD cells (recorded from six and four rats, respectively) was monitored under the following two different conditions: (1) in the cylinder, inside the curtained enclosure and (2) on the holding platform, outside the curtained enclosure. The animals were carried along the same path between the environments, always facing the direction of travel, so that they were never purposefully disoriented.

We examined the absolute angular difference between the preferred directions in conditions 1 (cylinder, inside the curtains) and 2 (holding platform, outside the curtains), for TPD $(n=13)$ and HD $(n=14)$ cells after correcting for sampling bias. The MLM corrected mean absolute difference was $20.0 \pm 3.6^{\circ}$ for TPD cells and $12.9 \pm 3.6^{\circ}$ for HD cells. No significant difference between these values was detected $(t=-1.53 ; p>0.1)$, showing that the directional constancy of TPD cells is comparable with that of HD cells.

The fact that the preferred directions of TPD cells do not vary across environments that share very few (if any) perceptual features suggests that TPD cells code for head direction in an allocentric framework, similarly to HD cells. It also suggests that idiothetic cues alone can maintain a stable directional signal in TPD cells, at least for the brief time required to move the rat across the curtains.

\section{Theta-modulated place-by-direction cell firing in different environments}

We recorded the activity of TPD cells in differently shaped environments, to understand how environmental boundaries determine theta-modulated place-by-direction firing and to compare the results obtained with those of place cells.

The environments used were as follows: (1) a cylindrical environment (cylinder), (2) a square environment (square), and (3) a circular platform without walls (open platform). All three of the environments were centered within the curtained enclosure of the laboratory. The average distance between the centers of the environments for the trials included in the analysis was small (2.5 


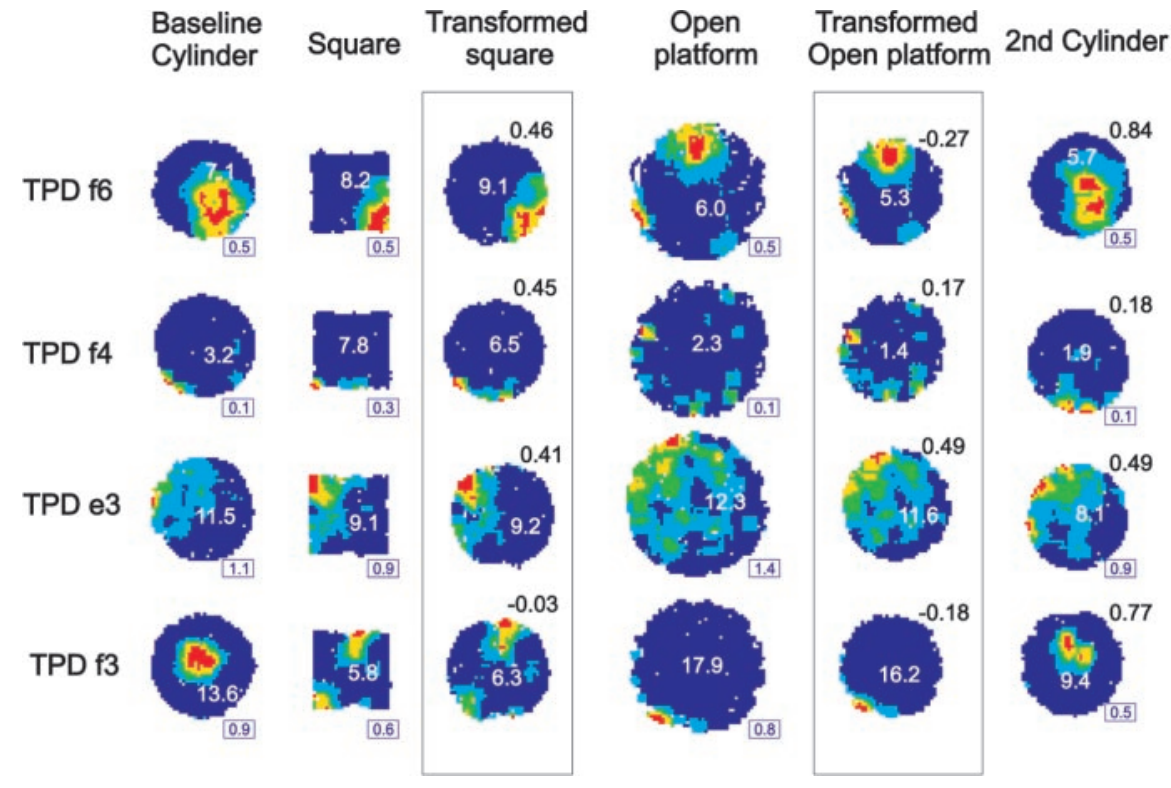

Figure 8. Firing-rate maps for four TPD cells comparing locational firing in each of the three different environments (cylinder, square, and open platform). Locational firing is reproducible across similarly shaped environments (baseline and second cylinder). In general, locational fields of TPD cells are similar across the cylinder and square but differ ("remap") between cylinder and open platform (see cells TPD f6 and f4; but for exceptions, see cells TPD e3 and TPD f3). For each cell, four untransformed and two topologically transformed firing-rate maps are presented. For square and open platform, topologically transformed maps are shown to the right of untransformed maps in the given environment. Correlation values, comparing with baseline cylinder, are shown in black, at the top right of transformed square, transformed open platform, and second cylinder firing-rate maps. Numbers in blue are as in Figure 2.

$\mathrm{cm})$. Therefore, firing patterns were compared directly, without needing to realign the maps. Thirty-eight TPD cells were included in this analysis. All three of the conditions were tested for 10 cells, the cylinder and square conditions were tested for seven cells, the cylinder and open platform were tested for 14 cells, and the remaining seven cells were recorded in the cylinder only. The cylinder condition was always tested at least twice (baseline and second cylinder), to estimate the intrashape variability in the locational firing of TPD cells.

\section{Intrashape stability of theta-modulated place-by-direction locational firing}

TPD locational firing is stable in repeated exposures to the same environment. Looking at the locational maps presented in Figure 8 , it is clear that the locational fields do not shift or change shape in baseline cylinder and second cylinder conditions. The correlation indices between firing-rate maps of two cylinder (for 34 cells), two square (six cells), and two open platform (11 cells) trials were computed. The average correlation values were $0.54 \pm$ 0.04 for the cylinder, $0.53 \pm 0.13$ for the square, and $0.47 \pm 0.06$ for the open platform. These values did not differ significantly $\left(F_{(2,48)}=0.359 ; p>0.1\right)$.

This result provides the grounds for the subsequent intershape analysis and confirms that the locational firing of TPD cells is stable across perceptually similar environments.

\section{Theta-modulated place-by-direction firing across differently} shaped environments

Directional component. For each TPD cell, we calculated the mean absolute angular difference in the preferred directions among the following: (1) baseline cylinder and second cylinder (15.0 $\pm 2.7^{\circ}$; $n=34$; as mentioned above), (2) baseline cylinder and square $\left(32.9 \pm 10.5^{\circ} ; n=17\right)$, and (3) baseline cylinder and open platform trials $\left(23.7 \pm 3.7^{\circ} ; n=22\right)$. The difference between these three values did not reach significance $\left(\right.$ ANOVA; $\left.F_{(2,70)}=2.50 ; p>0.05\right)$. We found no evidence for any systematic shift in the preferred directions of TPD cells nor for any difference in their directional selectivity, across these three comparisons (all three of the $p$ values $>0.1$ ).

These results show that the directional tuning of TPD cells is not substantially affected by the changes to environmental boundaries used in this study (Fig. 9) and suggest that any change in locational fields described below cannot be attributed to an alteration of the directional properties of the cell.

Locational component. Figure 8 shows the locational firing-rate maps for four TPD cells across the three environments tested. Both the raw and topologically transformed maps for square and open platform trials are presented to show how the topological transformation shapes the maps into cylinders. The general pattern is that locational fields are more similar across the cylinder and the square than across the open platform and the cylinder. The average correlation values between cylinder and square trials were $0.33 \pm 0.03$ $(n=17)$, and between cylinder and open platform the average correlation values were $0.16 \pm 0.04(n=24)$. The correlation values for cylinder-square comparisons are thus intermediate between those of cylinder-cylinder $(0.54 \pm 0.04)$ and cylinderopen platform. An ANOVA showed that the main effect of condition on the correlation values is significant $\left(F_{(2,72)}=28.72 ; p<\right.$ 0.001). Post hoc Scheffe's tests revealed that each condition differed significantly from each other $(p<0.05)$.

In summary, the results of the correlation analysis indicate that the degree of similarity between theta-modulated place-bydirection cell firing patterns is high in similarly shaped environments, intermediate across geometrically different bounded environments (cylinder and square), and low across the circular walled and unbounded environments (cylinder and open platform). This suggests that the walls of the environment are strong determinants of TPD cell locational firing, as they are for PCs (O’Keefe and Burgess, 1996; Lever et al., 2002a).

\section{Anatomical location}

TPD cells were recorded from a total of seven rats. We could identify the position of the electrode tracks in five of the seven animals. In the case of two animals (rats a and b contributing 28 and 5 TPD cells each), no electrode tracks were visible in the histological slides, possibly because of the long time elapsed (e.g., $>2$ months) between electrode implantation and the animal's death. Therefore, the anatomical locations of TPD cells recorded from animal a and $b$ can only be inferred from the implant coordinates [animal a, anteroposterior (AP), -6.7; mediolateral (ML), 3.0; dorsoventral (DV), 1.6; animal b, AP, 7.65; ML, 3.55; DV , 3.0] and electrode movement records. The most likely location for TPD cells was judged to be the deep layers of the dorsal presubiculum in these animals.

To clarify the anatomical location of TPD cells, most of the subsequent animals were killed immediately after a TPD cell was 


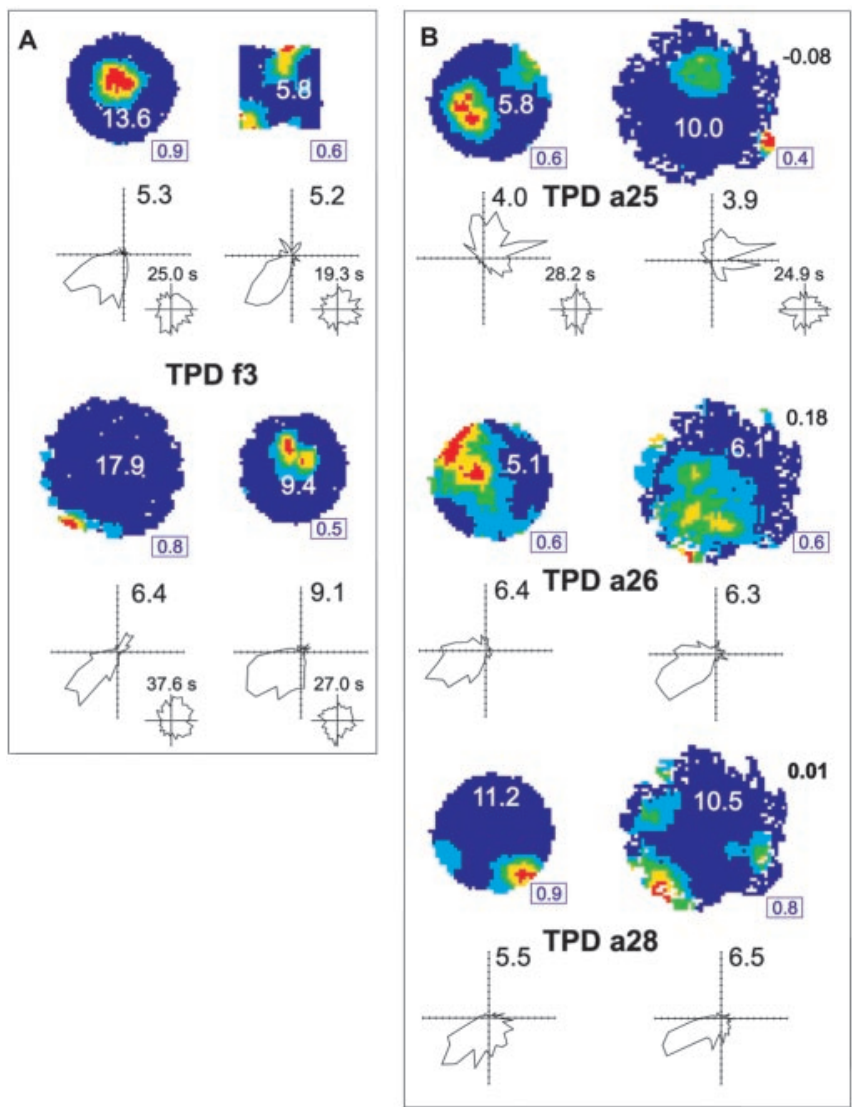

Figure 9. Similarity of preferred direction in different environments, despite remapping of preferred locational firing. $A, B$, For each TPD cell within each panel, locational firing is represented by firing-rate map (top) and directional firing by polar plot (bottom). Small polar plots (bottom right of each main polar plot) are as in Figure 2. Numbers in blue are as in Figure 2. $A$, TPD cell firing in canonical cylinder (top left), square (top right), open platform (bottom left), and second cylinder (bottom right) trials. B, Three simultaneously recorded TPD cells in the canonical cylinder (left) and open platform (right). Note that the similarity of TPD cell directional preference in different environments extends to those environments in which locational remapping is seen. Correlation values, compared with baseline cylinder, are shown in black at the top right of open platform locational maps.

Table 2. Anatomical locations of TPD cells

\begin{tabular}{ll}
\hline Cell & Anatomical location \\
\hline tda1-28 & (Best guess) deep layers of dorsal presubiculum \\
tdb1-5 & (Best guess) deep layers of dorsal presubiculum \\
tdc1 & Presubiculum \\
tdd1 & Superficial layers of either presubiculum or parasubiculum \\
tdd2 & Border between layers I and II of parasubiculum \\
tde1-2 & White matter above presubiculum \\
tde3 & Deep layers of presubiculum \\
tdf1-6 & Deep layers of presubiculum \\
tdf7 & Layer III of presubiculum \\
tdg1 & Below CA1 pyramidal layer \\
\hline
\end{tabular}

recorded; therefore, the number of cells recorded from these animals is low (animals c, d, e, and g). Table 2 summarizes the histological findings from all seven of the rats, whereas Figure 10 shows photomicrographs of the brain sections in which the electrode tracks are clearly visible.

TPD cells were most likely found in the deep and superficial layers of dorsal presubiculum ( $n=41$ or 42$)$ and only occasionally in the superficial layers of parasubiculum $(n=1$ or 2$)$ and the white matter overlying the dorsal presubiculum $(n=2)$. TPD and HD cells were sometimes recorded simultaneously from the same tetrode, indicating that these cell types are anatomically close in the brain. It was also often possible to record several TPD or HD cells at once, suggesting that these cells are organized in clusters within the brain structures listed above. One thetamodulated place-by-direction cell (TPD g1) was recorded from a location just below the CA1 pyramidal layer (data not shown).

Across the TPD cell population, both the position of locational fields and preferred directions were distributed evenly. Moreover, no obvious topographical relationship between anatomical position and firing pattern was observed (cells recorded simultaneously or sequentially along one electrode penetration did not show spatially related locational or directional properties). This could be established with some confidence, given that TPD cells tended to occur in clusters, i.e., in most cases, more than one TPD cell was recorded simultaneously. This was also true of HD cells. These clusters did not correspond to any obvious histological features.

\section{Qualitative observations}

Because this paper presents the first extended characterization of this cell type, we report some qualitative observations of TPD cell firing.

Passive transport of the animal did not cause any observable changes to the spatial properties of TPD cells. The preferred directions of two TPD cells recorded from different animals were found to be constant while the animal was moved by hand throughout the laboratory space $(3 \times 6 \mathrm{~m})$.

Two TPD cells were simultaneously recorded during a cuecontrol experiment, involving cue-rotation and cue-removal trials. The animal was not disoriented at any stage. After rotation of the cue card and the animal's point of entry by $90^{\circ}$, the locational and directional fields of both of the two cells rotated by $\sim 90^{\circ}$. When the cue card was removed from the environment, the directional and locational fields of the cells rotated slowly counterclockwise throughout the period of the trial (8 min). Again, both TPD cells maintained an approximately constant difference between their mean angles. The accumulated drift was $100^{\circ}$ (mean, $12.5^{\circ} / \mathrm{min}$ ). Thus, in the absence of the cue card, the remaining visual and other information was not sufficient for the TPD cells to maintain a stable representation of the environment. Because this animal ( $\mathrm{rat} \mathrm{b}$ ) had only previously been exposed three times to the curtained environment, perhaps the TPD system was not yet fully bound to background features but only to the most prominent cue in the environment.

Three TPD cells were recorded in the standard cylinder in total darkness (the audio speakers were also turned off). Interestingly, a strong or total suppression of firing was observed in two of three cells recorded from two animals. The cell whose firing was totally suppressed (TPDf3) (other correlates in Figs. 2, 8, 9) was simultaneously recorded with a head-direction cell that did not cease firing (its preferred direction drifting slowly clockwise).

An important difference between PC and TPD firing is that, although a PC will typically fire only in a subset of environments, all of the TPD cells recorded fired in every tested environment (with the sole exception of darkness). In this respect, TPD cells are more similar to subicular (Sharp and Green, 1994; Sharp, 1997; Sharp, 1999a) and medial entorhinal neurons (Quirk et al., 1992).

\section{Discussion}

The main result of the present study is that there exists a class of cells in the presubiculum and parasubiculum that codes for both 

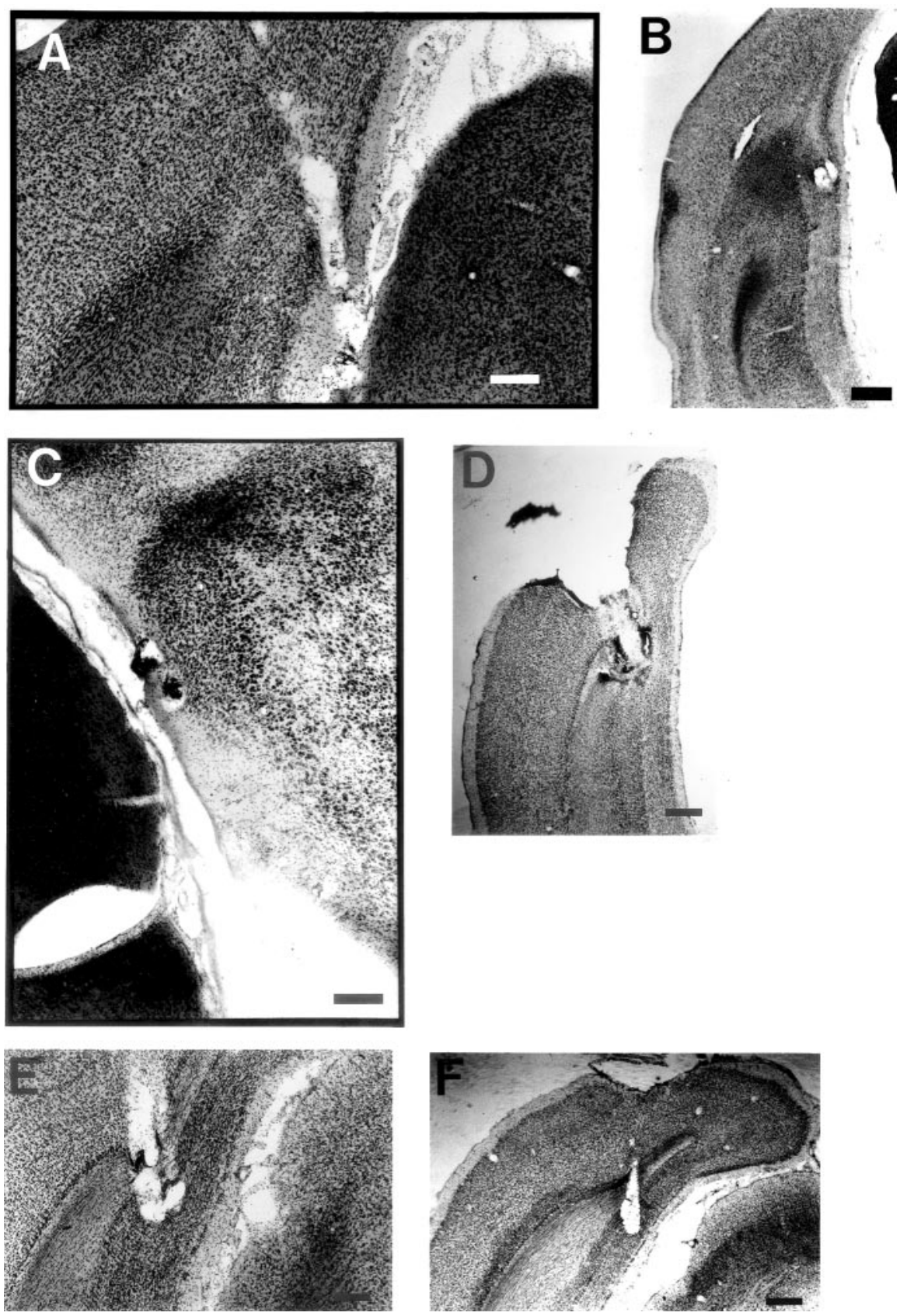

Figure 10. Photomicrographs of coronal sections showing electrode tracks in dorsal presubiculum and dorsal parasubiculum. A, Animal c. Electrode track through presubiculum (TPD c1). Scale bar, $310 \mu \mathrm{m}$. B, Animal d (left hemisphere). TPD d1 was recorded from the more lateral track of the two shown, from the superficial layers of either presubiculum or parasubiculum. Scale bar, $650 \mu \mathrm{m}$. C, Animal d (right hemisphere). TPD d2 was recorded from the more ventrolateral track of the two, from the superficial layers of caudal parasubiculum. Scale bar, $310 \mu \mathrm{m}$. D, Animal e. Large electrode track area made by four closely appositioned tetrodes. Tetrode tips are located in the deep layers of presubiculum. Before the animal's death, the electrodes were lowered $1 \mathrm{~mm}$ beyond the last TPD cell recording site. TPD cells may have been recorded from white matter dorsal to the presubiculum. Scale bar, $675 \mu \mathrm{m}$. E, Animal f. TPD and HD cells were recorded from both the lateral and medial tetrodes in layers III-VI of the presubiculum. Scale bar, $340 \mu \mathrm{m}$. F, Animal f. This section is $\sim 280 \mu \mathrm{m}$ anterior in the fixed brain to that in $E$. TPD f1 was recorded from this tetrode in the deep layers of presubiculum. Scale bar, $680 \mu \mathrm{m}$.

location and direction and whose firing is modulated by the theta oscillation. We characterized these cells, termed TPD cells. Our analyses indicate that there is a genuine locational and directional signal in TPD cell firing. The locational signal of a given TPD cell is environment specific, whereas its preferred direction is constant across different environments. (The directional signal appears to be slightly stronger than the locational signal in terms of information content.) We speculate that TPD cells mediate the integration of headdirection information into a thetamodulated navigational network.

\section{Directional and locational firing}

The preferred direction of TPD cells across different exposures to the same cylindrical environment is highly similar and comparable with that of HD cells. TPD preferred directions were also not significantly affected by changes to environmental boundaries. TPD cells also showed a directional constancy across differently located environments (the holding platform outside and the cylinder inside the curtained enclosure) that did not share obvious sensory cues. This directional constancy was similar to that of HD cells. In summary, TPD cells show similar directional preferences across both different environments in the same location and environments in different locations.

In contrast, the locational firing of TPD cells can clearly be altered by manipulations of environmental boundaries. TPD locational firing-rate maps were significantly more correlated across the cylinder-cylinder than across the cylindersquare conditions, and they were significantly more correlated across the cylinder-square than across the cylinderopen platform conditions. In other words, despite similar preferred directions across these environments, TPD cells often showed locational field "remapping" (Muller and Kubie, 1987), most clearly across the cylinder-open platform conditions. Thus, the locational and directional preferences of each TPD cell can be dissociated.

One implication of this dissociation is that it makes it more likely that the locational and directional components of TPD cell firing are derived from different sources. We do not know of a single cell type whose output TPD firing might simply reflect, in the way that, for instance, locational hippocampal theta cell firing reflects place-cell activity (Kubie et al., 1990; Marshall et al., 2002). For example, summation of several place-cell inputs would not result in similar preferred directions across different environments and would tend to result in lower, not higher, directional specificity than is obtained from a single place cell.

TPD firing is not explained as a theta-filtered summation of HD cell activity: unlike HD cells, TPD cells carry more robust and informative locational information. Furthermore, a strong reduction or total suppression of firing was observed in two of three TPD cells tested in darkness (recorded from two different animals), a result never seen in HD cells (Taube, 1998). We also note that there is only a very small directional signal in the firing of the 
location-specific subicular cells (Sharp and Green, 1994), at least in the open-field environments used in this study. Similarly, it is unlikely that the superficial entorhinal cells recorded by Quirk et al. (1992) carried significant directional information, because no directional correlates were reported. In general, therefore, TPD cell firing is not well characterized as a reflection of the output of one other type of spatial cell. Rather, TPD cell activity resembles an integration of location-related and direction-related information.

\section{Theta modulation}

Strong relationships exist between navigation and the theta oscillation, beyond the well known observation that locomotion produces theta (Vanderwolf, 1969). Unit recording has demonstrated that place cells code more accurately for location in theta mode (Kubie et al., 1985) than during the "large irregular activity" state (Vanderwolf, 1969), that hippocampal place cells exhibit phase precession through place-field traversals (O'Keefe and Recce, 1993), and concomitantly, that estimates of the animal's location are improved with knowledge of theta phase (Jensen and Lisman, 2000). In humans, theta episodes correlate with maze difficulty, path-error correction, and other variables, indicating an active navigational state (Caplan et al., 2001, 2003; Bischof and Boulanger, 2003). A similar finding in the rat is that place-based, but not cue-based, T-maze training modifies and augments basal theta activity (Olvera-Cortes et al., 2002). Accurate navigation, then, recruits circuitry that operates in theta mode.

TPD cells encode allocentric locational and directional information locked to the trough of the local theta wave. The present study provides the first demonstration, to our knowledge, of a robust allocentric orientation signal operating at theta frequency. Anterodorsal thalamic head-direction cells do not show theta modulation (Blair et al., 1999). Similarly, in Sharp's (1996) study of dorsal presubicular cells, of 26 cells classified by the regression analysis as head-direction cells, not one showed theta modulation. HD system information may need to be incorporated into, and distributed in, theta waves to be used for navigation. Presubicular TPD cells may be the first point at which this incorporation occurs.

The steps transforming brainstem signals into theta rhythmical activity in the hippocampal formation, via the hypothalamus and medial septum-diagonal band of Broca, have been well mapped out (for review, see Bland and Colom, 1993; Vertes and Kocsis, 1997; Bland and Oddie, 2001; Buzsaki, 2002). We briefly note here that another possible source of the theta modulation in TPD cells is the anteroventral thalamus, which has strong connectivity with the parasubiculum and presubiculum (Van Groen and Wyss, 1990a,b; Shibata, 1993). Up to 75\% of the cells recorded from this region fire rhythmically with theta, and many of these show a very deep theta modulation (Vertes et al., 2001).

The phase preference for TPD cell firing occurs at (or just before) the trough of the locally recorded theta oscillation. This is similar to interneurons recorded from the CA1 pyramidal layer (Csicsivari et al., 1999). The strength of theta modulation observed in TPD cells is comparable with that of septal cells, which help to drive hippocampal theta (being similar to type Ia cells, and only lower than type Ib cells) (King et al., 1998). Useful functions may arise from two information series impinging on target neurons at either slightly differing oscillatory frequencies (O'Keefe and Recce, 1993) or at different theta phases (Hasselmo et al., 2002). TPD cells might provide one of these oscillatory standards. If so, it may be important that each cell fires within a narrow oscillatory envelope and that TPD cells as a group share a similar and constant phase preference.

\section{Models}

TPD cells have similar properties to those of integrator cells postulated in several attractor network models of hippocampal function (McNaughton et al., 1996; Samsonovich and McNaughton, 1997; Sharp, 1999b). These models share the idea that any given environment is represented by a set of place cells that are linked together so that cells that fire in contiguous places are strongly interconnected by excitatory synapses, whereas place cells with widely separated fields are only weakly interconnected. A global inhibition mechanism guarantees that only one set of strongly interconnected place cells are active at any given time (representing a single location in the environment). An important element of these models is place-by-direction-by-movement cells that are responsible for shifting the location represented by place-cell activity, as the animal moves in the environment. Place-bydirection cells are also a necessary component of Brown and Sharp's (1995) stimulus-response navigation model.

TPD cells could be involved in place-field construction via a disynaptic entorhinal route to hippocampal cells (CaballeroBleda and Witter, 1994). The omnidirectional firing of a given place cell could result from summation of signals from several TPD cells having similar locational fields but different preferred directions. Evidence broadly consistent with this proposal is that lesions of the presubiculum (Calton et al., 2003), and combined lesions of the presubiculum and parasubiculum (Liu et al., 2004), reduce the omnidirectionality of, and/or degrade, hippocampal place-cell firing. Some models of place-field formation attempted to account for place-cell data by postulating inputs from two or more "boundary vector cells," whose firing is already nondirectional (Burgess et al., 2000; Hartley et al., 2000; Lever et al., 2002 b). The current proposal may be alternative or additional to such models, in suggesting the importance of directionally specific building blocks upstream of place cells.

\section{References}

Barnes CA (1988) Spatial learning and memory processes: the search for their neurobiological mechanisms in the rat. Trends Neurosci 11:163-169.

Bischof WF, Boulanger P (2003) Spatial navigation in virtual reality environments: an EEG analysis. Cyberpsychol Behav 6:487-495.

Blair HT, Cho J, Sharp PE (1999) The anterior thalamic head-direction signal is abolished by bilateral but not unilateral lesions of the lateral mammillary nucleus. J Neurosci 19:6673-6683.

Bland BH, Colom LV (1993) Extrinsic properties underlying oscillation and synchrony in the limbic cortex. Prog Neurobiol 2:152-208.

Bland BH, Oddie SD (2001) Theta band oscillation and synchrony in the hippocampal formation and associated structures: the case for its role in sensorimotor integration. Behav Brain Res 127:119-136.

Brown MA, Sharp PE (1995) Simulation of spatial learning in the Morris water maze by a neural network model of the model of the hippocampal formation and nucleus accumbens. Hippocampus 5:171-188.

Burgess N, Jackson A, Hartley T, O’Keefe J (2000) Predictions derived from modeling the hippocampal role in navigation. Biol Cybern 83:301-312.

Burgess N, Maguire EA, O'Keefe J (2002) The human hippocampus and spatial and episodic memory. Neuron 35:625-641.

Buzsaki G (2002) Theta oscillations in the hippocampus. Neuron 33:325-340.

Caballero-Bleda M, Witter MP (1994) Projections from the presubiculum and the parasubiculum to morphologically characterized entorhinalhippocampal projection neurons in the rat. Exp Brain Res 101:93-108.

Calton JL, Stackman RW, Goodridge JP, Archey WB, Dudchenko PA, Taube JS (2003) Hippocampal place cell instability after lesions of the head direction cell network. J Neurosci 23:9719-9731.

Caplan JB, Madsen JR, Raghavachari S, Kahana MJ (2001) Distinct patterns 
of brain oscillations underlie two basic parameters of human maze learning. J Neurophysiol 86:368 -380 .

Caplan JB, Madsen JR, Schulze-Bonhage A, Aschenbrenner-Scheibe R, Newman EL, Kahana MJ (2003) Human theta oscillations related to sensorimotor integration and spatial learning. J Neurosci 23:4726-4736.

Csicsivari J, Hirase H, Czurko A, Mamyia A, Buzsaki G (1999) Oscillatory coupling of hippocampal pyramidal cells and interneurons in the behaving rat. J Neurosci 19:274-287.

Ekstrom AD, Kahana MJ, Caplan JB, Fields TA, Isham EA, Newman EL, Fried I (2003) Cellular networks underlying human spatial navigation. Nature 425:184-187.

Fisher NI (1993) Statistical analysis of circular data. Cambridge, UK: Cambridge UP.

Frank LM, Brown EN, Wilson M (2000) Trajectory encoding in the hippocampus and entorhinal cortex. Neuron 27:169-178.

Hartley T, Burgess N, Lever C, Cacucci F, O'Keefe J (2000) Modeling place fields in terms of the cortical inputs to the hippocampus. Hippocampus 10:369-379.

Hasselmo ME, Bodelon C, Wyble BP (2002) A proposed function for hippocampal theta rhythm: separate phases of encoding and retrieval enhance reversal of prior learning. Neural Comput 14:793-817.

Huxter J, Burgess N, O'Keefe J (2003) Independent rate and temporal coding in hippocampal pyramidal cells. Nature 425:828-832.

Hyman JM, Wyble BP, Goyal V, Rossi CA, Hasselmo ME (2003) Stimulation in hippocampal region CA1 in behaving rats yields long-term potentiation when delivered to the peak of theta and long-term depression when delivered to the trough. J Neurosci 23:11725-11731.

Jarrard LE (1993) On the role of the hippocampus in learning and memory in the rat. Behav Neural Biol 60:9-26.

Jeffery KJ, O’ Keefe J (1999) Learned interaction of visual and idiothetic cues in the control of place field orientation. Exp Brain Res 127:151-161.

Jeffery KJ, Gilbert A, Burton S, Strudwick A (2003) Preserved performance in a hippocampal-dependent spatial task despite complete place cell remapping. Hippocampus 13:175-189.

Jensen O, Lisman JE (2000) Position reconstruction from an ensemble of hippocampal place cells: contribution of theta phase coding. J Neurophysiol 83:2602-2609.

King C, Recce M, O'Keefe J (1998) The rhythmicity of cells of the medial septum/diagonal band of Broca in the awake freely moving rat: relationships with behaviour and hippocampal theta. Eur J Neurosci 10:464-477.

Kubie JL, Muller RU, Fox SE (1985) Firing fields of hippocampal place cells: interim report. In: Electrical activity of the archicortex (Buszaki G, Vanderwolf CH, eds), pp 221-231. Budapest: Hungarian Academy of Science.

Kubie JL, Muller RU, Bostock E (1990) Spatial firing properties of hippocampal theta cells. J Neurosci 10:1110-1123.

Lever C, Wills T, Cacucci F, Burgess N, O'Keefe J (2002a) Long-term plasticity in hippocampal place-cell representation of environmental geometry. Nature 416:90-94.

Lever C, Burgess N, Cacucci F, Hartley T, O'Keefe J (2002b) What can the hippocampal representation of environmental geometry tell us about Hebbian learning? Biol Cybern 87:356-372.

Liu P, Jarrard LE, Bilkey DK (2004) Excitotoxic lesions of pre- and parasubiculum disrupt the place fields of hippocampal pyramidal cells. Hippocampus 14:107-116.

Marshall L, Henze DA, Hirase H, Leinekugel X, Dragoi G, Buzsaki G (2002) Hippocampal pyramidal cell-interneuron spike transmission is frequency dependent and responsible for place modulation of interneuron discharge. J Neurosci 22:RC197(1-5).

McNaughton BL, Barnes CA, Gerrard JL, Gothard K, Jung MW, Knierim JJ, Kudrimoti H, Qin Y, Skaggs WE, Suster M, Weaver KL (1996) Deciphering the hippocampal polyglot: the hippocampus as a path integration system. J Exp Biol 199:173-185.

Morris RG, Garrud P, Rawlins JN, O'Keefe J (1982) Place navigation impaired in rats with hippocampal lesions. Nature 297:681-683.

Muller RU, Kubie JL (1987) The effects of changes in the environment on the spatial firing of hippocampal complex-spike cells. J Neurosci 7:1951-1968.

Muller RU, Bostock E, Taube JS, Kubie JL (1994) On the directional firing properties of hippocampal place cells. J Neurosci 14:7235-7251.

O'Keefe J (1976) Place units in the hippocampus of the freely moving rat. Exp Neurol 51:78-109.
O'Keefe J, Burgess N (1996) Geometric determinants of the place fields of hippocampal neurons. Nature 381:425-428.

O'Keefe J, Nadel L (1978) The hippocampus as a cognitive map. Oxford: Clarendon. E-book available at www.cognitivemap.net.

O’Keefe J, Recce ML (1993) Phase relationship between hippocampal place units and the EEG theta rhythm. Hippocampus 3:317-330.

Olvera-Cortes E, Cervantes M, Gonzalez-Burgos I (2002) Place-learning, but not cue-learning training, modifies the hippocampal theta rhythm in rats. Brain Res Bull 58:261-270.

Paxinos G, Watson C (1986) The rat brain in stereotaxic coordinates. New York: Academic.

Quirk GJ, Muller RU, Kubie JL, Ranck J-BJ (1992) The positional firing properties of medial entorhinal neurons: description and comparison with hippocampal place cells. J Neurosci 12:1945-1963.

Robertson RG, Rolls EG, Georges-Francois P, Panzeri S (1999) Head direction cells in the primate pre-subiculum. Hippocampus 9:206-219.

Samsonovich A, McNaughton BL (1997) Path integration and cognitive mapping in a continuous attractor neural network model. J Neurosci 17:5900-5920.

Sharp PE (1996) Multiple spatial/behavioral correlates for cells in the rat postsubiculum: multiple regression analysis and comparison to other hippocampal areas. Cereb Cortex 6:238-259.

Sharp PE (1997) Subicular cells generate similar spatial firing patterns in two geometrically and visually distinctive environments: comparison with hippocampal place cells. Behav Brain Res 85:71-92.

Sharp PE (1999a) Subicular place cells expand or contract their spatial firing pattern to fit the size of the environment in an open field but not in the presence of barriers: comparison with hippocampal place cells. Behav Neurosci 113:643-662.

Sharp PE (1999b) Complimentary roles for hippocampal versus subicular/ entorhinal place cells in coding place, context, and events. Hippocampus 9:432-443.

Sharp PE, Green C (1994) Spatial correlates of firing patterns of single cells in the subiculum of the freely moving rat. J Neurosci 14:2339-2356.

Shibata H (1993) Direct projections from the anterior thalamic nuclei to the retrohippocampal region in the rat. J Comp Neurol 337:431-445.

Siegel JJ, Nitz D, Bingman VP (2000) Hippocampal theta rhythm in awake, freely moving homing pigeons. Hippocampus 10:627-631.

Skaggs WE, McNaughton BL, Gothard KM, Markus EJ (1993) An information-theoretic approach to deciphering the hippocampal code. Adv Neural Inf Process Syst 5:1030-1037.

Taube JS (1995a) Place cells recorded in the parasubiculum of freely moving rats. Hippocampus 5:569-583.

Taube JS (1995b) Head direction cells recorded in the anterior thalamic nuclei of freely moving rats. J Neurosci 15:70-86.

Taube JS (1998) Head direction cells and the neurophysiological basis for a sense of direction. Prog Neurobiol 55:225-256.

Taube JS, Muller RU, Ranck J-BJ (1990a) Head-direction cells recorded from the postsubiculum in freely moving rats. I. Description and quantitative analysis. J Neurosci 10:420-435.

Taube JS, Muller RU, Ranck J-BJ (1990b) Head-direction cells recorded from the postsubiculum in freely moving rats. II. Effects of environmental manipulations. J Neurosci 10:436-447.

Vanderwolf CH (1969) Hippocampal electrical activity and voluntary movement in the rat. Electroencephalogr Clin Neurophysiol 26:407-418.

Van Groen T, Wyss JM (1990a) The connections of presubiculum and parasubiculum in the rat. Brain Res 518:227-243.

Van Groen T, Wyss JM (1990b) The postsubicular cortex in the rat: characterization of the fourth region of the subicular cortex and its connections. Brain Res 529:165-177.

Vertes RP, Kocsis B (1997) Brainstem-diencephalo-septohippocampal systems controlling the theta rhythm of the hippocampus. Neuroscience 81:893-926.

Vertes RP, Albo Z, Viana Di Prisco G (2001) Theta-rhythmically firing neurons in the anterior thalamus: implications for mnemonic functions of Papez's circuit. Neuroscience 104:619-625.

Wills TJ, Cacucci F, Lever C, Burgess N, O'Keefe J (2004) Abrupt shift in hippocampal place cell representation from square-like to circle-like in a morph box. Soc Neurosci Abstr 30:330.10.

Wilson MA, McNaughton BL (1993) Dynamics of the hippocampal ensemble code for space. Science 261:1055-1058. 